\title{
On the Efficiency of Stock Markets: A Case of Selected OPEC Member Countries
}

\author{
Ebenezer A. Olubiyi ${ }^{1}$ and Peter O. Olopade ${ }^{2}$
}

The study investigates the stock market efficiency of selected OPEC member countries within the context of random walk hypothesis and volatility approaches using monthly data on stock market indices from January, 2005 to April, 2016. Parametric (variance ratio: homoskedastic and heteroskedastic martingale), nonparametric (the Wright ranks and scores) tests and $\mathrm{ARCH}$ type estimation are performed. Results of both parametric and nonparametric tests indicate that only Qatar's stock market is weak-form efficient. The volatility results suggest that monthly stock returns of OPEC countries are volatile, with Qatar being most volatile and shocks to volatility of stock returns are asymmetric. The implications of this are that: first, investors should be conscious of these shocks when making risk-return decision of their portfolios; second, the results provide useful information to regulators to enable them develop safeguard mechanisms to shield the market from possible asymmetric information emanating from the participants.

Keywords: Market Efficiency, Nonparametric Tests, Parametric Tests, Volatility

JEL Classification: G14, Q39, C14, C22

DOI: 10.33429/Cjas.09218.4/6

\subsection{Introduction}

The world market is witnessing progressive growth in recent times, evidenced by the world GDP growth rising from 2.0 percent in 2015 to 2.4 percent in 2016 and then to 3.0 percent in 2017 with an estimated growth of 3.1 percent in 2018 (World Bank, 2018). Consequently, the business environment is also showing signs of motivation for investors and this has has resulted in the listing of new, productive and profitable companies.

\footnotetext{
${ }^{1}$ Department of Economics, Federal University of Agriculture Abeokuta; Researcher: African Economic Research Consortium (AERC); Member: Trade Policy and Research programme, University of Ibadan: olubiyiea@funaab.edu.ng; Tel: +2348032184121.

${ }^{2}$ Graduate Student, Department of Economics Federal University of Agriculture Abeokuta: olopade.peter@yahoo.com.
} 
However, one important motivating factor for investing in equity is the ability to hedge risks and make more profit. Whether investors will be able to do this or not depends on the nature of efficiency of the market (Fama, 1970). Efficient market implies that the current price of a stock contains all past information such that no single investor can capitalize on any new information to make extra profit (Fama, 1970). Consequently, there will be no under/overvalued assets offering lower/higher than expected returns.

A special case of market efficiency hypothesis is the weak-form or the random walk hypothesis which states that stock price movements do not depend on past information and so, investors have no incentive to hedge risk they are exposed to. However, real-world experience has shown that some investors have been able to use past information to determine the future price and consequently, they have opportunities to earn a supernormal profit (Pandey, 2010).

This paper seeks to investigate the nature of market efficiency in the Organization of Petroleum Exporting Countries (OPEC) by looking at seven member countries. The motivation for studying the case of OPEC is: First, the oil sector has been linked to the economic performance of the oil producing nations. The OPEC is an Organization of 15 oil producing countries that coordinate and unify the petroleum policies of its members and also ensure oil market stabilization. These countries are: Algeria, Angola, Ecuador, Equatorial Guinea, Gabon, Iran, Iraq, Kuwait, Libya, Nigeria, Qatar, Congo, Saudi Arabia, United Arab Emirate (UAE) and Venezuela. Qatar has announced that it will pull out of OPEC in January 2019, on the ground that the country is planning to focus attention on the production of natural gas. Available evidence shows that the share of oil exports in total exports of these countries has been around 70 percent while its share in GDP has been on average, 38 percent in the last 10 years. Hence, any situation in the oil sector that alters the volume produced or price charged would influence economic activities which will in turn, affect the confidence of investors in the equity markets of the member countries (World Bank, 2017). Second, the demand for OPEC crude oil is expected to increase to about 40 million barrels per day $(40 \mathrm{mb} / \mathrm{d})$ in $2040 \mathrm{up}$ from $32 \mathrm{mb} / \mathrm{d}$ in 2018 while the growth rate of OPEC is estimated to increase 
from 1.8 percent in 2017 to 2.5 percent in 2018 but could drop to 2.3 percent in 2019 (This information was obtained from www.momr.opec.org/). Furthermore, many OPEC member countries like Qatar, Nigeria, Saudi Arabia, and UAE have prospects for high economic growth (Omoh et al., 2018). The rising demand for crude oil and promising economic growth could motivate investors to venture into the equity market of these countries. Third, the market capitalization of the oil companies in the OPEC countries was on average 44 percent (OPEC, n.d), suggesting that market capitalization of the oil sector could influence overall stock indices of these countries. Even if oil companies do not dominate the market, as long as the economy is promising, investors could decide to invest in equity of these countries. Another motivation stems from country-specific distortions in economic activity which could motivate investors to invest in other oil producing countries where such distortions are absent or less noticeable. The study by Guidi and Tarbert (2006) indicates that market returns of the UK and US are affected by business-based factors such as OPEC policy decisions during periods of conflict. These factors will certainly make stock market inefficient.

Stability of the stock returns helps investors to decide when and where to invest. However, given various country-specific distortions and/or frequent portfolio mix, the market may be volatile and the higher the volatility, the riskier the investments. Interestingly, volatility is a common phenomenon in well-developed financial markets, but most OPEC members have been identified as emerging markets indicating that the stock returns in these counties could exhibit or have the potential for high volatility. An emerging market is a market that have the potential to graduate to developed market or a market that is marked to become developed in the future (MSCI Emerging Markets Indexes available at www.msci.com). Providing further information about the behavior of the stock markets of OPEC member countries will help investors make adequate risk-return decision.

Many statistical methods have been advanced in testing the efficiency of stock markets. The methods range from unit root, stationarity, through variance ratio tests to volatility models and fractional integration technique. The unit root tests provide the necessary condition for efficiency while variance ratio provides sufficient 
condition, however, all these tests are nonparametric in nature. The use of volatility models, that is the generalized autoregressive conditional heteroskedasticity (GARCH) methods have been found useful not only to control for the influence of previous conditional variance or previous conditional mean (GARCH-M) but also for testing whether the shock to stock market returns is positive or negative and whether such positive (negative) shock more than neutralize other negative (positive) shock. Notwithstanding the weakness of the variance ratio tests, a significant number of authors have utilized it in studies of many countries and regions (see for example Urquhart and McGroarty, 2016; Guidi and Gupta, 2014; Jamaani and Roca, 2015).

This study carries out various variance ratio and volatility tests alongside the necessary condition for random walk in order to reveal the consistency or otherwise of the methods in investigating the efficiency of the stock market of selected OPEC member countries. Also, the existence and nature of the volatility of stock returns in this Cartel are established.

The organization of the rest of the article is as follows: section 2 provides a review of some of the existing literature. The data employed and as well as the methodology utilized in the study are presented in Section 3. Section 4 presents the results and discussions and section 5 concludes and provides some policy implications based on the underlying results.

\subsection{Literature Review}

\subsection{Theoretical Framework}

This work benefits from the efficient market hypothesis, commonly utilized to examine the efficiency of stock markets. The hypothesis was pioneered by Samuelson (1965), but was formally articulated and applied to the stock market by Fama (1970). They opine that stock markets are so efficient that no matter how smart investors are in accessing and using relevant information in the market, they cannot make any arbitrage profit through mispricing. There are two basic assumptions underlying the efficient market hypothesis: first, is that, stock prices move randomly so that it is difficult to predict its time path. In this case, the stock price 
exhibits random walk. Second, the random behavior of one stock price does not influence or is influenced by the randomness of another stock price movement; each stock price behaves independently of another.

Factors affecting random behavior of stock price are historical price, internal factor and external or public factors. These three also help to describe the nature of stock market efficiency. If all information contained in the previous stock price has been fully accounted for by the current price, then the market exhibits weakform efficiency. If, in addition to information inherent in the previous price, the current price also fully account for public information, then the market is semistrong efficient . The market will exhibit strong-form efficiency if, in addition to information inherent in the previous price, the current stock price also accounts for both internal and external information.

However, investors do engage in technical analysis to carefully read the perfect information available in order to make some profits, thereby casting doubt on the existence of weak-form efficiency. Also, since not all public information can be publicly accessible to all participants or it could take some time before such information is accessed by some, the semi-strong efficiency may not also hold.

\subsection{Empirical Review}

Empirical evidence on random walk hypothesis is voluminous, therefore, only the recent empirical papers are reviewed in this section. Aktan, Korsakiene, and Smalliukiene (2010) examine the characteristic of conditional volatility in the Baltic stock markets comprising of Estonia, Latvia and Lithuania. Their GARCH result on the data of stock market index between January 2, 2002, and March 1, 2009, shows that the stock returns of these countries exhibit asymmetry, long tail and complex autoregression. The implication of this is that past price of the stock in each of the countries can be used to predict the current price.

The use of the random walk hypothesis on the BRIC stock indices was examined by Jain, Vyas, and Roy (2013). They considered daily closing prices of S\&P CNX Nifty, BSE, CNX100, S\&P CNX 500 in studying the weak-form efficiency 
of Indian capital market during the period of global financial crisis. Both parametric and nonparametric tests ("ex-posts" in nature) are applied for the purpose of testing weak-form efficiency. The results suggest that the Indian stock market was weak-form efficient during the period of recession. The efficiency of the Gulf Cooperation Council (GCC) (Saudi Arabia, UAE, Kuwait, Oman, and Bahrain) stock markets was examined by Jamaani and Roca (2015). The daily stock market from December 2003 to January 2013 shows that the random walk hypothesis cannot be rejected suggesting that past price cannot predict current price.

Nwidobie (2014) tested the random walk hypothesis in share price movements in the Nigerian capital market by adopting the augmented Dickey-Fuller (ADF) test. The result rejects existence of the weak-form efficiency in Nigerian capital market. Graham, Peltomaki, and Sturludottir (2015) obtained data for Icelandic stock indices, that is, OMX16 alongside Denmark, Finland, Norway and Sweden stock markets from January 1993 to December 2013 to investigate market inefficiency over different periods of market controls. Utilizing various types of variance ratio tests (Chow-Denning Joint rank and sign variance ratio and Wild Boostrapping variance ratio), they found that Iceland and Finland that operate liberalized stock markets, are not efficiently better than others.

Andrianto and Mirza (2016) examined the movement of stock prices of listed companies on the Jakarta Islamic Index (JII) LQ45, and Kompas 100 Index. The findings show that Indonesian stock market is weak form efficient. Gil-Alana, Gupta, Shittu and Yaya (2018) were interested in the efficient market of Baltic countries comprising Estonia, Latvia and Lithuania based on historical data from January 1, 2000, to January 22, 2016. Using the usual classification of bull and bear phases and applying fractional integration approach, they found that Baltic markets do not follow random walk. However, when structural break was controlled for, random walk holds in two bull and one bear sub-samples.

Lee et al. (2018) obtained daily stock market data of 34 developed and emerging markets between January 1, 2003, and July 312007 to analyze the asymmetric market efficiency. Measuring the asymmetric market efficiency of the countries for 
different periods, it was found that most of the markets are efficient. However, when the markets are classified based on the asymmetric market efficiency, the source of asymmetry was revealed to be period-dependent. Rounagh and Zadeh (2016) employ Autoregressive moving average (ARMA) method to analyze the existence and dynamics of long memory nature of the S\&P 500 and London Stock Exchange using monthly and yearly data. The result shows that using ARMA for S\&P 500 gave better output than for London Stock Exchange. Comparing the result, both markets are weak-form efficient and have financial stability.

From the empirical works reviewed, literature on OPEC, as a cartel sharing the same economic characteristic is unavailable. As noted earlier, the stock markets of the OPEC countries are unique not only because of the dominance of oil producing companies in the respective financial markets but also as a result of growth prospect of the countries. Also, the financial markets of these countries are developing, therefore most of them are flagged as emerging markets. However, there are also series of country-specific economic challenges arising from the dynamics of world oil price, conflicts and other shocks. Investors interested in holding stock in OPEC member countries should have information about how these various shocks will affect their risk-return trade off. This study seeks to fill these gaps.

\subsection{Methodology}

\subsection{Data}

Monthly data on stock price indices of selected member countries of OPEC from January 2005 to April 2016 were obtained from the International Financial Statistics (IFS), published by the IMF. The dearth of stock market data for all the member countries restricts the numbers of countries to 7 and these are Iran, Kuwait, Nigeria, Qatar, Saudi Arabia, the UAE and Venezuela. These countries account for more than $50 \%$ of oil supply and GDP (in purchasing power parity form) of the cartel (see OPEC Data services department at momr.opec.org).

\subsection{Model Specification}

Stock returns are obtained by taking the log difference of stock prices. According to Brooks (2014), working with stock return removes the problem of unit of mea- 
surement. The stock return specification is provided in equation (1). The equation states that stock returns, $p$ is the log difference of stock price $P$, that is,

$$
p_{t}=100^{*} \ln \left(\frac{P_{t}}{P_{t-1}}\right)=100^{*}\left(\ln \left(P_{t}\right)-\ln \left(P_{t-1}\right)\right)
$$

The efficiency or otherwise of the stock market is linked to the presence of autocorrelation in the returns series. This implies that stock price return follows autoregressive process of the form provided in equation (2).

$$
p_{t}=\theta P_{t-1}+x \delta+\epsilon_{t}
$$

That is, stock price return $p$ at time $t$, depends on information from past stock price, an exogenous variable $x$, which is normally a constant or constant and trend, and the error term that is assumed to be pure white noise. The presence of unit root in equation (2) will require that the value of $\theta$ is greater than or equal to unity in absolute term. If $\theta$ is less than unity in absolute term, then the stock return is trend stationary.

Many tests have been advanced to test the values of $\theta$. For the purpose of this work, three of such tests are utilized and these are the Augmented Dickey-Fuller (ADF), Phillips- Perron (PP) and Kwiatkowski Schmidt Phillips and Shin (KPSS).

\subsection{Augmented Dickey-Fuller (ADF) unit root test}

The Augmented Dickey-Fuller unit root test was proposed to check the presence of unit root. If the ADF test validates the existence of unit root, then the price return is nonstationary and this provides evidence for the random walk. The basic $\mathrm{ADF}$ test for unit root is provided in equation (3):

$$
\Delta p_{t}=\theta p_{t-1}+x^{\prime} \delta+\beta_{1} \Delta p_{t-1}+\beta_{2} \Delta p_{t-2}+\beta_{3} \Delta p_{t-3}+\ldots . .+\beta_{j} \Delta p_{t-j}+\mu_{t}
$$

For this work, the ADF test for random walk is expressed in two ways. First is to assume that the random walk has a constant term and second, it has a constant and trend terms. The ADF with the constant term is given in equation (4) while the constant and trend counterpart is provided in equation (5). 


$$
\begin{gathered}
\Delta p_{t-1}=\alpha_{0}+\lambda p_{t-1}+\beta \sum_{i=1}^{j} \Delta p_{t-i}+\mu_{t} \\
\Delta p_{t-1}=\alpha_{0}+\alpha_{1} T+\lambda p_{t-1}+\beta \sum_{i=1}^{j} \Delta p_{t-i}+\mu_{t}
\end{gathered}
$$

In equations (4) and (5), $p_{t}$ follows an $A R(j)$ process. The null hypothesis is that equations (4) and (5) have unit roots.

\subsection{Phillips-Perron unit root test}

Phillip-Perron proposes long run variance using Newey-West estimation. The PP test is different from ADF due to the way the heteroskedasticity and autocorrelation are dealt with. Unlike the ADF, PP uses non-ADF regression and make adjustment for the existence of biasedness owing to possible correlations in innovation terms. The models for PP with constant and with constant and trend are specified in equations (6) and (7)

$$
\begin{gathered}
p_{t}=\alpha_{0}+\delta p_{t-1}+\mu_{t} \\
p_{t}=\alpha_{0}+\alpha_{1}\left(T-\frac{1}{2} r\right)+\delta p_{t-1}+\mu_{t}
\end{gathered}
$$

\subsection{The Kwiatkowsky Schmidt Phillips and Shin (KPSS) station- arity test}

Unlike the ADF and PP tests, the KPSS is specifically designed for testing the presence of stationarity, that is, the absence of unit root. The KPSS proceed in two steps. The first step is to estimate an OLS regression where the regressor is an exogenous variable (usually a constant or constant and trend) and the regressand is the stock return, p. The specification is provided in equation (8):

$$
p_{t}=x_{t} \delta+\mu_{t}
$$

The second step is to compute an LM statistics using the residual term in equation (8) and then use it to test the presence of stationarity (no random walk). The acceptance or rejection of the presence of unit root in any of the equations provides 
a necessary condition for random walk.

According to Gilmore and MacManus (2003), the unit root or stationarity tests does not account for the variance of the stock price returns which may correlate with the returns. Hence, these tests are considered as necessary condition for random walk hypothesis. The sufficient condition is the ability to control for variances of the stock market. There are many versions of variance ratio that account for the variances in stock returns but this study considers three, that is, the individual variance ratio proposed by Lo and McKinlay (1988), the multiple (or joint) variance ratio by Cho and Denning (1993), and the Wright (2000) tests.

\subsection{Variance Ratio test based on Lo and MacKinlay (1988)}

This test is based on the variance of the stock returns and the assumption is that the variance of the random walk increases linearly with time. The basic specification of the variance ratio (VR) is provided in equation (9).

$$
V R_{(q)}=\frac{\sigma^{2} q}{\sigma^{2} 1}
$$

That is, the variance ratio of lag $\mathrm{q}$ is the ratio of $\sigma^{2} q$ to $\sigma^{2} 1$. The $\sigma^{2} q$ is the unbiased estimator of $\frac{1}{q}$ of the variance of the $q^{\text {th }}$ difference and the $\sigma^{2} 1$ term is the variance at first difference. There are two versions of the variance ratio specified in equation (9). The first is the homoskedastic version which assumes that the error terms are independently and identically distributed (iid) and no normality condition is considered necessary. This is also called homoskedastic random walk hypothesis. The second version is based on the assumption that the variance of random walk term is time-dependent. This assumption allows for more general forms of conditional heteroskedasticity and dependence. A random walk that follows heteroskedastic conditional variance is also called the matingale hypothesis, that is, the hypothesis offers a set of sufficient conditions for the errors to be martingale difference sequence. From these two versions, it is possible to investigate whether returns on stock price follow an iid (homoskedastic) or martingale difference of sequence (heteroskedasticity). The specifications for the two versions are provided in equations (10) and (11): 


$$
z(q)=\frac{V R(q)-1}{\sqrt{v(q)}} \sim N(0,1)
$$

where

$$
\begin{gathered}
v(q)=\frac{[2(2 q-1)(q-1)]}{3 q(n q)} \\
z *(q)=\frac{V R(q)-1}{\sqrt{v *(q)}} \sim N(0,1)
\end{gathered}
$$

where,

$$
v *(q)=\sum_{k=1}^{q-1}\left[\frac{2(q-k)}{q}\right]^{2} \vartheta(k)
$$

where

$$
\vartheta(k)=\frac{\sum_{t=k+1}^{n q}\left(p_{t}-p_{t-1}-\hat{\mu}\right)\left(p_{t-k}-p_{t-k-1}-\hat{\mu}\right)^{2}}{\left[\sum_{t=1}^{n q}\left(p_{t}-p_{t-1}-\hat{\mu}\right)^{2}\right]^{2}}
$$

From equations (10) and (11), $z(q)$ and $z^{*}(p)$ statistics are tested against the null hypothesis that $\operatorname{VR}(\mathrm{q})=1$, suggesting that the chosen index (either $\mathrm{z}(\mathrm{q})$ or $z^{*}(p)$ ) is greater than the value of $\operatorname{VR}(q)$. If the null hypothesis is accepted based on equation (10), then the stock price returns follows homoscedastic random walk. If it is accepted based on equation (11), then it follows martingale difference sequence random walk.

\subsection{The Wright Test}

The conventional variance ratio test suggests that the series are normally distributed. However, when series of stock prices are not normally distributed, in which case, it is right (or left) skewed, these variance ratios will be of little help for random walk analysis. Wright (2000) developed a non-parametric variance ratio based on ranks and signs. This approach is capable of dealing with small sample size and or non-normal distribution challenges.

There are two forms of the Wright test, namely, the ranks and signs (Urquhart and McGroharty, 2016). To develop the test, $r 1$ is assumed to be the log of return, $p(r)$ is the rank of $r(p)$ among $(r 1, r 2, \ldots, P r)$. Under the null hypothesis, $r i$ is iid, 
that is, a random permutation of numbers $1,2,3, \ldots, T$ with equal probability for each $t$. Given this information, the rank-based variance ratio tests, that is, $R 1$ and $R 2$ is specified in equations (12) and (13)

$$
\begin{aligned}
& R_{1}(q)=\left(\frac{\frac{1}{T} \sum_{t=q}^{T}\left(r_{1 t}+\ldots+r_{1 t-q+1}\right)^{2}}{\frac{1}{T} \sum_{t=1}^{T} r_{1 t}^{2}}-1\right) \Theta \sqrt{(q)} \\
& R_{2}(q)=\left(\frac{\frac{1}{T} \sum_{t=q}^{T}\left(r_{2 t}+\ldots+r_{2 t-q+1}\right)^{2}}{\frac{1}{T} \sum_{t=1}^{T} r_{2 t}^{2}}-1\right) \Theta \sqrt{(q)}
\end{aligned}
$$

where

$$
\begin{gathered}
\Theta \sqrt{(q)}=\sqrt{\left(\frac{2(2 q-1)(q-1)}{3 q T}\right)} \\
r_{1 t}=\frac{r\left(p_{t}\right)-\frac{(T+1)}{2}}{\frac{\sqrt{[(T-1)(T+1)]}}{12}} \\
r_{21 t}=\Phi^{-1}\left(\frac{r\left(p_{t}\right)}{T+1}\right)
\end{gathered}
$$

where $\Phi^{-1}$ is the inverse of the standard normal cumulative distribution function and $T$ is the first difference of the variable $p_{t}$

Under the signs-based first difference is provided in equation (12)

$$
S_{j}(q)=\left[\frac{(T q)^{-1} \sum_{t=q}^{T}\left(s_{j t}+, \ldots,+s_{i t-q+1}\right)^{2}}{T^{-1} \sum_{t=1}^{T} s_{j t}^{2}}-1\right] \sqrt{\left(\frac{2(2 q-1)(q-1)}{3 q T}\right)}
$$

where $s_{1}=2 u\left(p_{t}, 0\right)$ and $u\left(p_{t}, 0\right) \frac{1}{2}$ is the if $p_{t}$ is positive and if negative, the value will be- $\frac{1}{2}$.

\subsection{The ARCH-type test}

The Wright test actually solves the problem of normality and small sample problems but it also lost the parametric information needed for decision making. Besides, all the tests did not model conditional heteroskdasticity and this cast doubt 
on their efficiency. In order to correct for this, the autoregressive conditional heteroskedasticity (ARCH)-type was proposed; starting from the Engle's (1982) AR effect of the form:

$$
p_{t}=\alpha_{0}+\alpha_{1} p_{t-1}+\mu_{t}
$$

The squared of the estimated residual is estimated using the lag of the residual, that is,

$$
\mu_{t}^{2}=\pi_{0}+\pi_{1} \mu_{t-1}^{2}+v_{t}
$$

The null hypothesis is that there is no autoregressive conditional heteroskedasticity $(\mathrm{ARCH})$ effect. This hypothesis is tested using the F-statistic or the nR2, where $\mathrm{n}$ is the number of observations. The significance of the F-statistics or the $\mathrm{nR} 2$ will suggest the rejection of the null hypothesis of no $\mathrm{ARCH}$ effect. In this regard, the stock returns are said to be volatile.

But the variance of residuals of most high frequency series such as stock returns are not constant because the error terms of the past period tend to influence the current variance (Engle, 1982). To deal with this problem, the mean and variance of the series are estimated simultaneously. Suppose the series of stock returns could be lagged $q$ times, then the mean and variance can be estimated with the following models:

$$
\begin{gathered}
p_{t}=\alpha_{0}+\sum_{i=1}^{q} \alpha_{i} p_{t-i}+\mu_{t} \\
\sigma_{t}^{2}=\pi_{0}+\sum_{i=1}^{q} \pi_{i} \mu_{t-i}^{2}
\end{gathered}
$$

Equation (18) says that the variance of the residual at time $t$ is explained by the squared of the lagged error term. The $\mu_{t-i}^{2}$ is the ARCH term and we expect the estimator, $\pi_{i}$ to take on a positive value less than 1 . The closer the value of the estimator to 1 , the slower the mean reverting and vice versa. 
Bollerslev (1986) however argues that the conditional variance in equation (18) could be influenced by its lagged values, particularly when dealing with high frequency macroeconomic series. The equation is therefore modified to capture the influence of lagged conditional variance

$$
\sigma_{t}^{2}=\pi_{0}+\sum_{i=1}^{q} \pi_{i} \mu_{t-i}^{2}+\sum_{j=1}^{z} \lambda_{j} \sigma_{t-j}^{2}
$$

This is the well-known generealized ARCH-type (GARCH) model. The second term on the right hand side of equation (19) is the $\mathrm{ARCH}$ effect while the third is the GARCH effect. Again, the sum of the estimators of ARCH and GARCH terms should assume a positive value strictly less than 1 to be sure that the shock is temporary, otherwise the shock is permanent. The closer the sum to 1 the slower the mean reverting (the less the shock is temporary). In the event that it is zero, the model reduces to ARCH(q). Meanwhile, the conditional mean could be influenced by its own conditional variance but not that the conditional variance is affected by its lagged values. This ARCH-type is very important when analyzing volatility in the financial markets because it removes the news inherent in the variance of the residuals. This ARCH-type is called GARCH-M and is specified below:

$$
p_{t}=\alpha_{0}+\sum_{i=1}^{q} \alpha_{i} p_{t-i}+\mu_{t}+\delta \sigma_{t}^{2}
$$

The focus is on the value of $\delta$. If the value is not significantly different from zero, then no GARCH-M effect, otherwise it is useful to capture the dependence of the returns on its own variance.

All the GARCH considered assume that news in the markets are symmetric. But asymmetry is also inevitable and such news could be positive (good news) or negative (bad news). To deal with this situation, Zakoian (1994) developed a threshold GARCH (TGARCH) of the form

$$
\sigma_{t}^{2}=\pi_{0}+\sum_{i=1}^{q} \pi_{i} \mu_{t-i}^{2}+\sum_{j=1}^{z} \lambda_{j} \sigma_{t-j}^{2}+\varphi \mu_{t-j}^{2} * D_{t-1}
$$

where $D_{t-1}$ is a dummy variable interacted with the squared of the lagged residuals. The dummy checks for how significant the shock (news) is. If lag of the error 
term is negative, then $D_{t-1}$ assumes a value of 1 . If however the value is positive or zero it assumes zero. If $\varphi$ is significantly different from zero, then the shock (either positive or negative) is very important in influencing the volatility.

Although TGARCH sheds more light on how important the news is, it does not indicate whether the effects of good news on the stock returns volatility overweighs the bad news. This information is needed by the investors. To control for this, Nelson (1991) proposed an exponential GARCH (EGARCH) which is specified below

$$
\ln \left(\sigma_{t}^{2}\right)=\pi_{0}+\pi_{1}\left|\left(\frac{\mu_{t-1}^{2}}{\sigma_{t-1}^{2}}\right)^{\frac{1}{2}}\right|+\beta\left(\frac{\mu_{t-1}^{2}}{\sigma_{t-1}^{2}}\right)^{\frac{1}{2}}+\zeta \ln \left(\sigma_{t-1}^{2}\right)
$$

The focus here is on the value of $\beta$. If it is less than zero then the negative shock (bad news) overweighs the positive shock (good news). If it is greater than zero, then the positive shock (good news) overweighs the negative shock (bad news). If $\beta$ is zero then the market information is symmetric.

In order to choose the model among the ARCH-type, that best show the nature of volatility of the stock returns in each of the OPEC countries under review, the Schwartz Information Criterion (SIC) was employed. The choice of this test was informed by the heavy weights it placed on the loss of degree of freedom and the sample size. The lowest value of SIC gives the best model.

The data are tested for both necessary and sufficient conditions for the existence of efficiency using equations (4)-(13) and the presence and nature of volatility using equations (16)-(22).

\subsection{Results and Discussions}

\subsection{Properties of the series}

The properties of the stock price returns of selected OPEC member countries is presented in Table 1. The expected returns range between $0.006 \%$ in Iran to $4.2 \%$ in Venezuela. Hence, Venezuela had the highest expected stock returns among the OPEC countries under study. Nigeria's expected stock return was about $0.53 \%$ 
while that of UAE was $0.11 \%$. The lowest expected returns observed in Iran was consistent with the work of Jamaani and Roca (2015). The maximum stock returns ranged between $0.01 \%$ in Iran and $11.5 \%$ in Venezuela. The maximum stock returns in Nigeria, Qatar and Kuwait were $0.84 \%, 0.08 \%$ and $0.04 \%$ respectively.

Table 1: Descriptive Statistics of the series across countries ${ }^{3}$

\begin{tabular}{lccccccc}
\hline & KUWAIT & NIGERIA & IRAN & QATAR & SAUDI & UAE & VENEZUELA \\
\hline Mean & 0.024 & 0.527 & 0.006 & 0.042 & 0.049 & 0.108 & 4.176 \\
Median & 0.026 & 0.567 & 0.006 & 0.042 & 0.050 & 0.103 & 4.928 \\
Maximum & 0.036 & 0.835 & 0.011 & 0.082 & 0.083 & 0.163 & 11.572 \\
Minimum & 0.013 & 0.180 & 0.003 & 0.027 & 0.019 & 0.059 & 0.038 \\
Std. Dev. & 0.007 & 0.170 & 0.001 & 0.010 & 0.013 & 0.029 & 3.230 \\
Skewness & -0.119 & -0.358 & 0.178 & 0.938 & 0.009 & 0.127 & 0.213 \\
Kurtosis & 1.754 & 2.239 & 5.327 & 4.526 & 2.940 & 1.540 & 2.164 \\
\hline Jarque-Bera & 8.982 & 6.098 & 30.952 & 32.639 & 0.022 & 12.259 & 4.915 \\
Probability & 0.011 & 0.047 & 0.000 & 0.000 & 0.989 & 0.002 & 0.086 \\
\hline ARCH(q) [1] & $164.06 * * *$ & $224.03 * * *$ & $6.676^{* * *}$ & $22.14 * * *$ & $57.98^{* * *}$ & $35.76^{* * *}$ & $44.26 * * *$ \\
Observations & 134 & 134 & 134 & 134 & 134 & 134 & 134 \\
\hline *** ** and * & r & & 134 &
\end{tabular}

***;** and ${ }^{*}$ represents $1 \% ; 5 \%$ and $10 \%$ significance levels, respectively

Note, in the results, the number of lag $(q)$ varies across countries, the Schwartz (lag selection) information criterion (SIC) was used to get the appropriate lag for each country and the maximum lag (8) occurred in Qatar while the minimum lag (4) occurred in Venezuela. The literature predicts that stocks that have high expected returns should be associated with high risk. A glance at the result shows that Venezuela's stock returns was the highest and it goes with the highest risk (standard deviation). Similarly, Nigeria's stock was the second in terms of returns and thus, represented the second most risky stock. Conversely, Iran had the lowest return but this is also associated with lowest risk hence, this study confirms the theoretical proposition of risk-return tradeoff in the selected OPEC countries. The skewness of returns was positive for all the countries except Kuwait and Nigeria.

\footnotetext{
${ }^{3}$ The number of lag (q) varies across countries. the Schqartz (lag selection) information criterion (SIC) was used to get the appropriate lag for each country. The maximum lag (8) occurred in Qatar while the minimum (4) occurred in Venezuela. The justification for choosing SIC among others such as HQC, AIC, LR and FPEis based on the sample size. When the sample size is greater than 60, the appropriate lag selection criterion is HQC and SIC. But SIC have been found to perform better particularly when the observation exceeds 120 (Lowe, 2004; Ashgar and Abdi, 2007)
} 
For these countries with positive skewness, asymmetric tail extend further towards positive monthly returns than negative. This provides first hand information about the possible normality of the monthly stock returns. In the countries with negative skewness, the asymmetry tail extends further towards negative monthly return than positive, providing a first-hand information about possible non-normality of the stock returns. The monthly Kurtosis is higher than 3 in two countries (Iran and Qatar), indicating that in these countries, the monthly return distribution has fatter tails. Virtually all the series are not normally distributed except the monthly stock return of Saudi Arabia. To test for the existence of conditional heteroskedasticity, that is, short run variance, the LM test was applied to the residuals of the estimated Autoregressive moving average (ARMA). The result clearly shows that the monthly stock returns of the OPEC countries under study significantly exhibit short run variance.

The result of the unit root and stationarity tests are presented in Table 2. The ADF, PP and KPSS are tested at level.

Table 2: Results of unit root and stationarity tests

\begin{tabular}{|c|c|c|c|c|c|c|c|}
\hline Countries & KUWAIT & NIGERIA & IRAN & QATAR & SAUDI-ARABIA & UAE & VENEZUELA \\
\hline \multicolumn{8}{|c|}{ ADF Test } \\
\hline Constant & -0.75 & -1.11 & $-3.25 * *$ & -2.32 & -2.12 & -1.83 & -0.95 \\
\hline Constant and Trend & -1.68 & -1.56 & -3.2 & -2.48 & -2.22 & -1.82 & -3.07 \\
\hline \multicolumn{8}{|c|}{ PP Test } \\
\hline Constant & -0.7 & -1.2 & $-4 * * *$ & -2.6 & -2.4 & -1.7 & -1.9 \\
\hline Constant and Trend & -2 & -1.6 & $-3.7 * *$ & -2.8 & -2.2 & -1.6 & -3.3 \\
\hline \multicolumn{8}{|c|}{ KPSS Test } \\
\hline Constant & $1.08 * * *$ & 0.3 & 0.22 & $0.46^{* *}$ & 0.34 & 0.28 & $1.21 * * *$ \\
\hline Constant and Trend & $0.17 * *$ & 0.1 & 0.13 & $0.18^{* *}$ & $0.25^{* * *}$ & $0.28 * * *$ & 0.1 \\
\hline
\end{tabular}

Note: **, ** indicate rejection of the null hypothesis at 1\%, and $5 \%$ respectively. The null hypothesis for ADF and PP is that the series has unit root while the null hypothesis for KPSS is that the series is stationary 
Table 3: Variance Ratio test result based on Lo and MacKinlay $(1988,1989)$

\begin{tabular}{|c|c|c|c|c|}
\hline $\begin{array}{l}\text { Number of months q, } \\
\text { in holding period }\end{array}$ & 2 & 5 & 10 & 30 \\
\hline \multicolumn{5}{|l|}{ KUWAIT } \\
\hline $\operatorname{VR}(q)$ & 1.38 & 2.07 & 2.58 & 2.00 \\
\hline$z(q)$ & $4.46 * * *$ & $5.7 * * *$ & $5.43 * * *$ & 1.89 \\
\hline$z^{*}(q)$ & $1.81 * * *$ & $2.47 * * *$ & 2.53 & 0.74 \\
\hline \multicolumn{5}{|l|}{ NIGERIA } \\
\hline $\operatorname{VR}(q)$ & 1.23 & 1.73 & 2.14 & 1.50 \\
\hline$z(q)$ & $2.67 * *$ & $3.81 * * *$ & $3.87 * * *$ & 0.93 \\
\hline$z^{*}(q)$ & $1.81^{*}$ & $2.47 * *$ & $2.53 * *$ & 0.74 \\
\hline \multicolumn{5}{|l|}{ IRAN } \\
\hline $\operatorname{VR}(q)$ & 1.28 & 1.70 & 1.56 & 0.63 \\
\hline$z(q)$ & $3.27 * * *$ & $3.71 * * *$ & $1.94^{*}$ & -0.7 \\
\hline $\mathrm{z}^{*}(\mathrm{q})$ & $2.61 * *$ & $3.44 * * *$ & $2.42 * *$ & -0.40 \\
\hline \multicolumn{5}{|l|}{ QATAR } \\
\hline $\operatorname{VR}(q)$ & 1.03 & 1.03 & 0.9 & 0.21 \\
\hline$z(q)$ & 0.36 & 0.90 & -0.30 & -1.50 \\
\hline $\mathrm{z}^{*}(\mathrm{q})$ & -0.10 & 0.14 & -0.10 & -1.20 \\
\hline \multicolumn{5}{|l|}{ SAUDI-ARABIA } \\
\hline $\operatorname{VR}(q)$ & 1.21 & 1.35 & 1.31 & 0.55 \\
\hline$z(q)$ & $2.45 * *$ & $1.86^{*}$ & 1.05 & -0.80 \\
\hline$z^{*}(q)$ & $1.42 *$ & $1.4^{*}$ & 1.14 & -0.80 \\
\hline \multicolumn{5}{|l|}{ UAE } \\
\hline $\operatorname{VR}(q)$ & 1.29 & 1.44 & 1.52 & 0.79 \\
\hline$z(q)$ & $3.36 * * *$ & $2.31 * *$ & $1.78 *$ & -0.40 \\
\hline$z^{*}(q)$ & $1.71 *$ & 1.08 & 1.11 & -0.60 \\
\hline \multicolumn{5}{|l|}{ VENEZUELA } \\
\hline $\operatorname{VR}(q)$ & 1.26 & 1.21 & 0.57 & 0.38 \\
\hline$z(q)$ & $2.94 * *$ & 0.71 & -0.80 & -0.90 \\
\hline$z^{*}(q)$ & $2.68 * *$ & $3.2 * * *$ & $3.83 * * *$ & $4.42 * * *$ \\
\hline
\end{tabular}

The result from the ADF, PP and KPSS tests are mixed across countries. Random walk was observed in all the countries, for ADF and PP tests, except in Iran (Table 2). When KPSS test was utilized, the result is slightly different. In this regard, for Kuwait and Qatar stock returns, we reject the null hypothesis of the presence of stationarity, at $1 \%$ and $5 \%$ level of significance both with constant and 
constant and trend. For Saudi Arabia and UAE stock returns, the null hypothesis of the presence of stationarity cannot be accepted at $1 \%$ level of significance with constant and trend.

The unit root and stationarity tests are necessary conditions for random walk while the variance ratio provides sufficient condition. Invoking equations (10) and (11), the result of the variance ratio is provided in Table 3. In order to be consistent with the Wright lag selection, this study chose 2, 5, 10 and 30 lags, with the consideration of homoskedastic and heteroskedastic nature of each country's stock returns' residuals. The result suggests that the monthly returns of Kuwait, Nigeria, Iran, UAE and Venezuela at lags 2, 5 and 10 rejects the random walk hypothesis. The homoskedastic random walk hypothesis in these countries shows significantly positive serial correlations in lags 2, 5 and 10. The Martingale hypothesis, also holds for all the countries, albeit at different lags. For instance, it is only in the 2nd and 5th lags that the series follows Martingale difference in Kuwait and Saudi Arabia. In Venezuela, the homoskedastic hypothesis can only be established at the 2nd lag while the Martingale difference is established in lags 2, 5 and 10. In UAE, the monthly series is more of homoscedastic than heteroskedastic. The null hypothesis for the presence of random walk of Qatar monthly stock returns cannot be rejected even after controlling for the presence of time-dependent variance.

Specifically, the stock price returns of Kuwait, Nigeria, Iran, Saudi Arabia, UAE and Venezuela are not weak-form efficient. But the stock return of Qatar is weakefficient. These results corroborate the work of Jamaani and Roca (2015) who established the weak-form efficiency of the Qatar stock returns among other GCC countries. 
Table 4: Variance Ratio test result based on Wright (2000)

\begin{tabular}{|c|c|c|c|c|}
\hline Q & 2 & 5 & 10 & 30 \\
\hline \multicolumn{5}{|l|}{ KUWAIT } \\
\hline Ranks & $3.586 * * *$ & $4.032 * * *$ & $3.850 * * *$ & 0.300 \\
\hline Ranks Score & $3.873 * * *$ & $4.6467 * * *$ & $4.517 * * *$ & 1.000 \\
\hline Signs of data & $3.012 * * *$ & $2.766 * * *$ & $2.258^{*}$ & 0.000 \\
\hline \multicolumn{5}{|l|}{ NIGERIA } \\
\hline Ranks & $3.172 * * *$ & $3.737 * * *$ & $3.788 * * *$ & 0.700 \\
\hline Ranks Score & $3.053 * * *$ & $3.892 * * *$ & $3.979 * * *$ & 0.700 \\
\hline Signs of data & $2.959 * * *$ & $3.369 * * *$ & $3.629 * * *$ & $0.633 * * *$ \\
\hline \multicolumn{5}{|l|}{ IRAN } \\
\hline Ranks & $2.587 * * *$ & $3.068 * * *$ & $2.129^{*}$ & -1.000 \\
\hline Ranks Score & $3.185^{* * *}$ & $3.929 * * *$ & $2.638 * * *$ & -1.000 \\
\hline Signs of data & $2.496^{*}$ & $2.766^{*}$ & $2.513^{*}$ & 1.300 \\
\hline \multicolumn{5}{|l|}{ QATAR } \\
\hline Ranks & -0.400 & -0.300 & -0.160 & -1.000 \\
\hline Ranks Score & -0.200 & -0.140 & -0.2 & $-1.553 * * *$ \\
\hline Signs of data & -0.900 & -1.020 & -0.940 & -1.000 \\
\hline \multicolumn{5}{|c|}{ SAUDI ARABIA } \\
\hline Ranks & 1.330 & 1.250 & 0.972 & -1.000 \\
\hline Ranks Score & 1.470 & 1.290 & 0.821 & -1.000 \\
\hline Signs of data & 0.870 & 0.440 & 0.804 & 0.000 \\
\hline \multicolumn{5}{|l|}{ UAE } \\
\hline Ranks & 1.100 & 1.430 & 1.513 & 0.000 \\
\hline Ranks Score & 1.650 & 1.640 & 1.697 & 0.000 \\
\hline Signs of data & 0.520 & 0.760 & 0.691 & 0.000 \\
\hline \multicolumn{5}{|l|}{ VENEZUELA } \\
\hline Ranks & $3.111 * *$ & $2.869^{* *}$ & $1.959^{*}$ & 1.300 \\
\hline Ranks Score & $3.115^{* * *}$ & $3.014 * * *$ & $1.853 *$ & 1.400 \\
\hline Signs of data & $2.785 * * *$ & $2.988^{*}$ & $2.629 *$ & 1.400 \\
\hline
\end{tabular}

The results from the Wright tests are different from the earlier ones, this could be as a result of the correction of the non-normality condition. In Table 4, Kuwait, Nigeria, Iran and Venezuela's stock market prices exhibit significant serial correlation, indicating that there is a strong relationship between past and current stock movement. On the other hand, the stock returns of Saudi Arabia and UAE are not weak-form efficient. Hence it is clear that normality condition can actually provide wrong information regarding stock returns that exhibit non-normality. Meanwhile, the stock price return in Qatar is consistently weak-form efficient. 
This study goes further to model predictability of stock price returns using ARCHtype approach. This method improves on the variance ratio tests in at least two ways: first it corrects for generalized conditional variance; second, it provides reliable estimates of the parameters which helps to predict the direction of shock to the stock returns.

Table 5 presents the results with various ARCH-type. Each ARCH-type model in bold font represents the best model, as indicated by SIC. Many interesting results emerge from Table 5: first, in virtually all the countries, previous monthly stock price significantly influences current monthly prices. Second, not all the stock return exhibit ARCH and/or GARCH effect. Third, for most of the stock returns, TGARCH and EGARCH have superior predictability power. Only in Iran and Saudi Arabia did GARCH-M have superior predictive power.

The best model for Kuwait monthly stock return is the EGARCH-type, suggesting that asymmetry shock to stock return volatility exists. The coefficient of the asymmetry is significant and positive, indicating that the good news in the stock market of Kuwait overweighs the bad news. Further, the value of ARCH coefficient is close to 1 indicating that the mean reverting of stock returns in Kuwait is slow.

In Nigeria, even though the asymmetry in EGARCH model was positive and significant, TGARCH performs better but the asymmetry coefficient is insignificant. Thus the news (shock) to the monthly stock returns volatility is symmetric and permanent, suggesting that to some extent, stock returns of Nigeria is inefficient.

Iranian stock market is not very volatile. The GARCH-M shows the best predictability power but the conditional mean was not affected by its own conditional variance. Meanwhile, the coefficient of the ARCH effect is significant and greater than 1 . Hence, the stock returns is not mean reverting and the shock is permanent. 
Table 5: Monthly Stock Returns Volatility of Selected OPEC Countries

\begin{tabular}{|c|c|c|c|c|c|c|c|c|c|c|c|}
\hline \multirow[b]{2}{*}{ COUNTRIES } & \multirow[b]{2}{*}{ MODEL/ARCH-TYPE } & \multicolumn{3}{|c|}{ MEAN EQUATION } & \multicolumn{5}{|c|}{ VARIANE EQUATION } & \multicolumn{2}{|c|}{$\begin{array}{c}\text { POST } \\
\text { ESTIMATION } \\
\end{array}$} \\
\hline & & CONSTANT & $\alpha_{1}$ & $\begin{array}{r}\text { GARCH-M } \\
\text { EFFECT ( } \delta)\end{array}$ & $\begin{array}{c}\text { CONSTANT } \\
\left(\pi_{0}\right)\end{array}$ & $\begin{array}{c}\operatorname{ARCH} \\
\operatorname{EFFECT}\left(\pi_{1}\right)\end{array}$ & $\begin{array}{l}\text { GARCH(1) } \\
\operatorname{EFFECT}(\lambda)\end{array}$ & $\begin{array}{l}\text { ASSYMETRIC } \\
\text { EFFECT }(\phi)\end{array}$ & $\begin{array}{c}\text { ASSYMETRIC } \\
\text { IMPORTANCE } \\
(\zeta)\end{array}$ & SIC & $\begin{array}{l}\text { ARCH LM } \\
\text { TEST }\end{array}$ \\
\hline \multirow{4}{*}{ KUWAIT } & GARCH (1 1 1) & 0.021 & $0.979 * * *$ & & 0.001 & 0.150 & 0.599 & \multirow{4}{*}{0.199} & & -2.954 & 0.987 \\
\hline & GARCH-M & -0.011 & $1.009 * * *$ & 0.056 & $0.001 * * *$ & $0.753^{* * *}$ & 0.012 & & & -3.184 & 0.955 \\
\hline & TGARCH & -0.008 & $1.009 * * *$ & & $0.001^{* * *}$ & $0.636 * * *$ & 0.011 & & & -3.185 & 0.953 \\
\hline & EGARCH & -0.014 & $1.016^{* * *}$ & & $-3.486 * * *$ & $0.666^{* * *}$ & 0.023 & & $0.521^{* * *}$ & -3.21 & 0.986 \\
\hline \multirow{4}{*}{ NIGERIA } & GARCH (1 11$)$ & 0.004 & $0.991 * * *$ & \multirow{4}{*}{0.008} & 0.001 & 0.150 & $0.599 * *$ & \multirow{4}{*}{0.148} & & -3.285 & 0.345 \\
\hline & GARCH-M & $-0.014^{* * *}$ & $1.018^{* * *}$ & & 0.000 & $0.835^{* * * *}$ & $0.446 * * *$ & & & -4.737 & 0.971 \\
\hline & TGARCH & $-0.013 * * *$ & $1.016 * * *$ & & $0.000^{* * *}$ & $1.504^{* * *}$ & $0.298^{* * *}$ & & & -5.039 & 0.946 \\
\hline & EGARCH & $-0.012 * * *$ & $1.014 * * *$ & & $-1.985 * * *$ & $0.626^{* * *}$ & 0.116 & & $0.782^{* * *}$ & -4.099 & 0.972 \\
\hline \multirow{4}{*}{ IRAN } & GARCH (lll) & $0.005^{* * *}$ & $0.294^{* * *}$ & \multirow{4}{*}{-0.046} & $0.000^{* * *}$ & $1.188^{* * * *}$ & -0.03 & \multirow{4}{*}{0.027} & & -11.866 & 0.937 \\
\hline & GARCH-M & $0.004 * * *$ & $0.474 * * *$ & & 0.000 & $1.446^{* * *}$ & 0.074 & & & -12.043 & 0.619 \\
\hline & TGARCH & $0.005^{* * *}$ & $0.293 * *$ & & $1.170^{* * *}$ & $-0.031 * * *$ & 0.027 & & & -11.832 & 0.937 \\
\hline & EGARCH & $0.0001^{* * *}$ & $0.986 * *$ & & -0.044 & $0.939^{* * *}$ & -0.073 & & $1.049^{* * *}$ & -11.899 & 0.196 \\
\hline \multirow{4}{*}{ QATAR } & GARCH (1 11$)$ & 0.081 & $0.915 * * *$ & \multirow{4}{*}{-0.173} & 0.005 & 0.150 & 0.597 & \multirow{4}{*}{$-0.619^{* * *}$} & & -1.749 & 0.000 \\
\hline & GARCH-M & 0.065 & $0.938 * *$ & & 0.000 & $0.313^{* * *}$ & $0.703 * * *$ & & & -2.339 & 0.794 \\
\hline & TGARCH & $0.062^{* * * *}$ & $0.935 * * *$ & & $0.001^{* * *}$ & $0.768^{* * *}$ & $0.510^{* * *}$ & & & -2.36 & 0.451 \\
\hline & EGARCH & $0.069 * * *$ & $0.927^{* * *}$ & & $-0.921 * * *$ & $0.486^{* * *}$ & $0.142^{* *}$ & & $0.898^{* * *}$ & -2.385 & 0.648 \\
\hline \multirow{4}{*}{ SAUDI ARABIA } & GARCH (lll) & 0.024 & $0.957 * * *$ & \multirow{4}{*}{0.039} & 0.008 & 0.150 & 0.600 & \multirow{4}{*}{-0.313} & & -1.312 & 1.000 \\
\hline & GARCH-M & 0.002 & $0.957^{* * *}$ & & $0.002^{* * *}$ & $2.300^{* * * *}$ & -0.003 & & & -1.928 & 1.000 \\
\hline & TGARCH & 0.008 & $0.977^{* * *}$ & & $0.007 * * *$ & 0.294 & $0.545^{* * *}$ & & & -1.463 & 1.000 \\
\hline & EGARCH & 0.004 & $0.973 * * *$ & & $--4.639 * * *$ & $2.251^{* * *}$ & $0.659 * *$ & & $0.378^{* * *}$ & -1.862 & 1.000 \\
\hline \multirow{4}{*}{ UAE } & GARCH (l 11$)$ & 0.003 & $0.973 * * *$ & \multirow{4}{*}{0.026} & 0.000 & 0.150 & $0.600^{* * *}$ & \multirow{4}{*}{-0.123} & & -7.818 & 0.724 \\
\hline & GARCH-M & 0.003 & $0.970^{* * *}$ & & $0.000^{* * * *}$ & $0.250^{* * *}$ & $0.760^{* * * *}$ & & & -7.826 & 0.839 \\
\hline & TGARCH & $0.003^{* * *}$ & $0.963 * * *$ & & $0.000^{* * *}$ & $0.265^{* * *}$ & $0.777^{* * *}$ & & & -7.818 & 0.724 \\
\hline & EGARCH & $0.002^{* * * *}$ & $0.976 * * *$ & & -0.00514 & $0.697 * * *$ & 0.03239 & & $1.055^{* * *}$ & -8.37 & 0.720 \\
\hline \multirow{4}{*}{ VENEZUELA } & GARCH (ll 1 l) & -0.008 & $0.984 * * *$ & \multirow{4}{*}{-0.196} & 0.006 & 0.150 & 0.595 & \multirow{4}{*}{$-0.171^{* * * *}$} & & -1.592 & 0.005 \\
\hline & GARCH-M & 0.000 & $0.971 * * *$ & & 0.000 & $0.221^{* * *}$ & $0.742 * * *$ & & & -4.767 & 0.759 \\
\hline & TGARCH & 0.000 & $0.950^{* * * *}$ & & 0.000 & $0.087^{* * * *}$ & $0.926^{* * *}$ & & & -4.927 & 0.534 \\
\hline & EGARCH & -0.002 & $0.994^{* * *}$ & & $-7.07909^{* * * *}$ & $1.866^{* * * *}$ & $0.19272^{* *}$ & & $-0.206 * * *$ & -4.789 & 0.797 \\
\hline
\end{tabular}

Qatar and UAE's monthly stock returns are mean reverting, faster in UAE than Qatar. The effect of the good news on the stock return volatility overweighs the bad news. Saudi Arabia's monthly stock return also shows the importance of information asymmetry but the SIC indicates that GARCH-M is the preferred model. The $\mathrm{ARCH}$ effect is greater than 1, indicating that the shock to volatility is permanent.

Incidence of shock is very important in the Venezuelan stock market. Although negative news tends to absorb positive news, TGARCH performs better. Further, the asymmetric news to volatility is negative, implying that negative shock is very important in the market. The sum of $\mathrm{ARCH}$ and $\mathrm{GARCH}$ are close to 1, suggesting that the mean reverting tendency is very slow.

Comparing these results with the variance ratio results, and particularly the Wrightstype variance ratio, Kuwait, Nigeria and Qatar are consistent. That is, Kuwait and Nigeria stock market are consistently not weak-form efficient, only to add that the 
good news in the stock price volatility more than offset the bad news in Kuwait. In Qatar, variance ratio tests indicate that the stock market is weak-form efficient while the volatility test indicate that the prices are volatile, mean reverting but the positive shock overweighs the negative shock. Given the fact that ARCH-type test is superior to variance ratio tests in terms of predictability power due to control of conditional heteroscedasticity and ability to quantify the magnitude and direction of effect (parametric), it can be said that monthly stock prices of Kuwait, Nigeria, Saudi Arabia, UAE and Iran do not exhibit weak-form efficiency hypothesis while that of Qatar and Venezuela are weak-efficient and volatile.

\subsection{Conclusion and Policy Implications}

This study tests the weak-form efficiency hypothesis of the stock markets of some selected OPEC members by utilizing batteries of tests and ARCH-type estimation for volatility. The risk-return tradeoff was established in the stock markets of the countries under review. Venezuela stock market indicates the highest expected return but also is the riskiest. Conversely, Iran had the lowest monthly expected returns but also with the lowest risk. Results of the various variance ratios indicate that the weak-form efficiency hypothesis is validated in Qatar. The implication of this is that except in Qatar stock market, other OPEC stock markets in our sample countries are inefficient. Consequently, the previous stock price can be used to predict the current stock price. This result is consistent with the work of Jamaani and Roca (2015), Urquhart and McGroarty (2016), Gil-Alana et al. (2018) and Lee et al. (2018).

The volatility results indicate that monthly stock returns of selected OPEC countries are volatile, mean reverting and of course asymmetric news influence the volatility. However, monthly stock prices are less volatile in Iran, Kuwait, Nigeria, UAE, Saudi Arabia and Venezuela, while it is highly volatile in Qatar. Further, TGARCH and EGARCH have superior power of prediction over other ARCH-type models. This result is in support of Bala and Takimoto (2017).

Some implications can be drawn from these results. First, efficiency of the equity market affords a theoretical and predictive model useful for the operation in the 
equity market that will help investors, particularly in the economies that share the same characteristics such as the oil producing countries (Jamaani, 2015; Lee et al., 2018; and Bala and Takimoto, 2017)). This information will enable them to identify possible mispriced assets, so that they can adjust their risk-return trade-off. The regulator will also benefit from efficient equity market because it will act as a safeguard mechanism to shield the market from possible asymmetric information emanating from the participants and by implication dwarf regional and global investment capital flows. The results from this study is expected to provide useful information to participants in the equity markets of the OPEC members.

Furthermore, the result from the non-parametric and parametric tests provide robust information for investors engaging in equity investment in the oil-rich countries. For instance, oil-based stocks are the driving force of economic growth of the oil-rich OPEC. Hence, our results suggest that the intending investors can easily recognize mispriced OPEC stocks by simply observing the previous price changes within the OPEC member countries' stock markets.

\section{References}

Afego, P. (2012). Weak form-efficiency of the Nigerian stock market: An empirical analysis (1984-2009). International Journal of Economics and Financial Issues, pp. 340-347

Andrianto, Y and Mirza, A. (2016). A testing of efficient markets hypothesis in Indonesia. Social and Behavioral Science, Vol. 219, pp. 99-103

Aktan, B., Korsakiene, R. and Smaliukiene, R. (2010). Time-varying volatility modelling of Baltic stock markets. Journal of Business Economics and Management, Vol. 11 No. 3, pp. 511-532

Ashgar, Z. and I. Abdi (2007). Performance of lag length selection criteria in three different situations. Interstat, No. April 2007. Available at www.impra.ubu.umi.muenchen.de

Azad, A. S. (2009). Random walk and efficiency tests in the Asia-Pacific foreign exchange markets: Evidence from the Post-Asian currency crisis data. Research in International Business and Finance, Vol. 23 No. 3, pp. 322-338

Bollerslev, T. (1986). Generalized autoregressive conditional heteroskedasticity. Journal of Econometrics, Vol. 31, pp. 307-327. 
Brooks, C. (2014). Introductory econometrics for finance, Third Edition. Cambridge University Press, London.

Charles, A. I. and Dame, O. (2009). The random walk hypothesis for Chinese stock markets: Evidence from variance ratio test. Economic Systems, Vol. 33, pp. $117-126$

Chow, K.V. and Denning, K. C. (1993). A simple multiple variance ratio test. Journal of Econometrics, Vol. 58, pp. 385-401

Engle, R. F. (1982). Autoregressive conditional heteroskedasticity with estimates of the variance of United Kingdom Inflation. Econometrica, Vol. 50 No. 4, pp. 987-1007.

Fama, E. F. (1970). Efficient capital markets: A review of theory and empirical work. Journal of Finance, Vol. 25 No. 2, pp. 383-417

Fan, Y. and Gençay, R. (2010). Unit root tests with wavelet. Economic Theory, Vol. 26, pp. 1305-1331

Gimba, V. K. (2012). Testing the weak-form efficiency market hypothesis: Evidence from Nigeria stock market. CBN Journal of Applied Statistics, Vol. 3 No. 1, pp. 117-136

Gil-Alana, L. A., Gupta, R., Shittu, O. I. and Yaya, O. S. (2018). Market efficiency of Baltic stock markets: A fractional integration approach. Physica A, Vol. 511 No. 1, pp. 251-262

Gilmore, C. G., and McManus, G. M. (2003). Random-walk and efficiency tests of Central European equity markets. Managerial Finance, Vol. 2 No. 4, pp. $42-61$

Graham, M. Peltomaki, J and Sturludottir, H. (2015). Do market controls affect stock market efficiency? Lessons from Iceland. International Review of Financial Analysis, doi: 10.1016/j.irfa.2015.05.009.

Guidi, F. and Gupta, R. (2014). Are ASEAN stock market efficient? Evidence from univariate and multivariate variance ratio tests. Griffith Business School Discussion Papers in Finance, 2011-13.

Guidi, M. and Tarbert, H. (2006). The effect of OPEC policy decisions on oil and stock prices. OPEC Energy Review, Vol. 30 No. 1, pp.1 - 18.

Jain, P., Vyas, V. and Roy, A. (2013). A study on weak form of market efficiency during the period of global financial crisis in the form of random walk on Indian capital market. Journal of Advances in Management Research, Vol. 10 No. 1, pp. $122-138$. 
Jamaani, F. and Roca, E. (2015). Are the regional Gulf stock markets weak-form efficient as single stock markets and as a regional stock market? Research in International Business and Finance, 33, 221-246. https://doi.org/10.1016/j.ribaf.2014.09.001

Lee, M, Song, J, Kim S and Chang, W. (2018). Asymmetric market efficiency using the index-based asymmetric-MFDFA. Physica A, 512, 1278-1294. https://doi.org/10.1016/

Liew, V. (2004). Which of the lag length selection criteria should we employ? Economics Bulletin. 3 (3), 1-9

Lagoarde-Segot, T. and Lucey, B. M. (2006). Efficiency in emerging markets Evidence from the MENA region. International Financial Markets, Institutions and Money, Vol. 18 No. 1, pp. 94-

Liu, C. Y. and He, J. (1991). A variance-ratio test of random walks in foreign exchange rates. The Journal of Finance, Vol. 46 No. 2, pp. 773-785

Lo, A.W. and MacKinlay, A. C. (1988). Stock price do not follow random walks: Evidence from specification test. Review of Financial Studies, Vol. 1, pp. $41-66$

Nneji, I. (2013). Efficiency of the Nigerian capital market; An empirical analysis. Research Journal of Finance and Accounting, Vol. 4 No. 4, pp. 69-77

Nwodibe, B. M. (2014). The random walk theory: An empirical test in the Nigerian capital market. Asian Economic and Financial Review, Vol. 4 No. 2, pp. $1840-1848$.

Nwosa, S. and Oseni, J. E. (2011). Efficient market hypothesis and Nigeria stock market. Research Journal in Finance and Accounting, Vol. 2 No. 12, pp. $38-46$

Obayagbona, J and Igbinosa, S. O. (2015). Test of random walk hypothesis in Nigeria stock market. Current Research Journal of Social Sciences, Vol. 7 No. 2, pp. 27-36

Omoh, J., Nwachukwu, T. and Mbanafor, O. (2018). Economic growth in OPEC member oil exporting earning versus non-oil exporting earning. Developing Country Studies Vol. 8 No. 2

OPEC (2016). Organization of Petroleum Exporting Countries Data Service Department. Available at www.momr.opec.org/

Pandey, I. . (2010). Financial management. New Delhi: Vikas Pubs.

Rounagh, M and F. Zadeh (2018). Investigation of market efficiency and financial stability between S\&P500 and London Stock Exchange: Monthly and yearly forecasting of time series stock return using ARMA model. Physica A, Statistical Mechanics and Applications. Vol. 456, pp. 10-21 
Samuelson, P. A. (1965). Proof that properly anticipated prices fluctuate randomly. Industrial Management Review, Vol. 6 No. 2, pp. 41-49

Tiwari, A and Kyophilavong, P. (2014). New evidence from the random walk hypothesis for BRICs stock indices: A wavelet unit root test approach. Economic Modelling, Vol. 43, pp. 38-41

Urquhart, A and MaGroarty, F. (2016). Are stock markets really efficient? Evidence from adaptive market hypothesis. International Review of Financial Analysis, doi:10.1016/jirfa,.2016.06.011

Wright, J.H. (2000). Alternative variance-ratio tests using ranks and signs. Journal of Business and Economic Statistics, Vol. 18 No. 1, pp. 1-9

World Bank (2018). Global economic prospect: Broad-based upturn, but for how long? The World Bank Group, Washington D.C.

Zhang, M and Cheng, Q. (2005). An approach to VAR for capital markets with Gaussian mixture. Applied Mathematics and Computation, Vol. 168 No.2, pp. 1079-1085.

Zakoian, J. M (1994). Threshold heteroskedasticity models. Journal of Economic Dynamics and Control, Vol. 18, pp. 931-955. 